\title{
Attributes of Internal Audit and Prevention, Detection and Assessment of Fraud in Pakistan
}

\author{
Naveed Khan*, Abdul Rafay ${ }^{* *}$ and Amer Shakeel ${ }^{* * *}$
}

\begin{abstract}
With it being considered as a value-added activity, the Internal Audit function (IAF) of a firm is one of the most important functions in an organization. During the last decade, the role of this particular function has become very useful, especially in creating awareness regarding the Prevention, Detection and Assessment (PDEA) of fraudulent activities. In many countries, carrying out an Internal Audit is a legal compulsion for public companies, in order to establish an effective, and efficient IAF. This study aims to explore the relationship between the various attributes of IAF (effectiveness, independence, staff training, qualification and experience), and the PDEA of fraudulent activities in Pakistan. For this purpose, the convenient sampling technique, for data collection, is used and the questionnaires are collected from the respondents belonging to Pakistan. The questionnaire has been prepared in the form of a Likert scale. Respondents for this study include (1) staff members working in the Internal Audit (IA), finance and accounting departments of the companies listed on the Pakistan Stock Exchange (PSX), and (2) staff members of firms that are engaged in external statutory audit in Pakistan. Descriptive statistics show the details regarding the demographic questions, IAF and PDEA of the fraudulent activities that take place in the companies. Moreover, in order to get to the effective and relevant results, the regression analysis is performed in order to find out if there exists any relationship between these variables. The results show that all five independent variables positively affect the PDEA of fraudulent activities. However, three of the independent variables (IAE, IAT, and IAQ) are statistically significant, whereas two of the variables taken into account (IAI, and IAE) are statistically insignificant. It is recommended that the IAF should be more independent, and effective so as to attain the required results. Moreover, firms should also focus on the qualifications and proper training of the staff that are responsible for executing the IAF.
\end{abstract}

Keywords: Internal auditor, training, independence, qualification.

JEL Classification: M41, M42, M49

\footnotetext{
${ }^{*}$ Research Scholar, University of Management \& Technology (UMT), Pakistan.

${ }^{* *}$ Professor, University of Management \& Technology (UMT), Pakistan.

${ }^{* * *}$ Assistant Professor, University of Management \& Technology (UMT), Pakistan.
} 


\section{Introduction}

With the rise in crime, fraudulent practices, and a general attitude of dishonesty in individuals, seeping into every aspect of our life, the global communities have also experienced a dramatic increase in the illegal and fraudulent conduct of businesses (Repousis, Lois, \& Veli, 2019). As a result, fraud has become one of the most critical obstacles that hinder the growth and progressive development of an organization (Azim \& Azam, 2016). Over a period of time, fraud has become a key issue in many corporate bodies (George, Theofanis, \& Konstantinos 2015), and is now a global business risk affecting the profitability of the organizations. Gates, Prachyl, \& Sullivan, (2016) studied that seventy percent of businesses reported at least one fraudulent practice in its internal operations. The factors that contribute towards an activity, qualifying as fraud, are weak corporate governance, functional irregularities, weak internal control systems, insatiability, and the lack of business values and ethics (Soltani, 2014). There are multiple mediums that can be used in order to detect fraudulent activities and practices in organizations. Some of these include whistleblowing, tips, and an internal and external audit, to name a few (Lee \& Fargher, 2013).

Due to the exponential increase in the fraudulent scandals, and the often occurring financial crisis, there is now more demand for an Internal Audit Function (IAF) in the companies (Bekiaris, Efthymiou \& Koutoupis, 2013). Leung, Cooper, and Perera (2011) explained that an Internal Audit (IA) is an independent activity that is resorted to, in order to add value in the organizations' operations, primarily by bringing a systematic and disciplined approach towards the operations of the company. A disciplined and systematic approach towards conducting the IAF proves to be beneficial for the organization, in order to achieve the goals of transparency. An effective IAF proves helpful, (1) to improve the risk management systems of an organization (El-Sayed Ebaid, 2011), (2) in the application of the accounting system in the organization, (3) in the effective implementation of auditing standards (Balaciu, Bogdana, Feleaga \& Popa, 2014), (4) for the executive directors, and the employees in performing their responsibilities (Daniela, 2013), (5) to support the assessment of the work, and suggest improvements in the control and governance processes, (6) in reducing fraudulent financial reporting, and lastly, (7) in reporting weaknesses in Internal Control (IC) systems (Prawitt, Sharp \& Wood, 2012).

A person who is responsible for conducting for audits is called an Internal Auditor. The basic role of an Internal Auditor (I-Auditor) is the 


\section{Fraud in Pakistan}

PD\&A of fraudulent activities. The effectiveness of the IAF depends upon the competence of the staff members, support by the top management, and the independence of the IAF (George et al., 2015). The access to ample training opportunities, and the subsequent practical abilities of the members may also enhance the performance of the IAF (Alvarez, 2012). The independent and impartial IAF can provide guidance to the management for making sure that there are consistently successful and flawless operations of the company. In their study, Drogalas, Pazarskis, Anagnostopoulou, and Papachristou (2017) explained that the basic purpose of the IAF is to ensure that the accounting system, as well as the IC system, are functioning appropriately at all times. The IAF is responsible for various activities that help ensure the smooth operations of a firm. The first one of these is to safeguard the assets of the company. The second one is to prevent the manipulation of funds, while the third one is to detect and prevent any fraudulent activities. Lastly, the fourth activity is to minimize the losses which occur due to any negligence in practice of safe and effective business operations (Al Matarneh, 2011; Monisola, 2013).

\subsection{Significance of this study for Pakistan}

In the year 2018, the Association of Fraud Examiners (ACFE) conducted a study which included 5 countries from South Asia, including Afghanistan, Bangladesh, India, Maldives, and Pakistan. A total of 96 fraud cases from these countries (including 13 cases from Pakistan) were brought under critical examination. Moreover, a Median Loss of USD 100,000, due to occupational fraud, was reported from the cases examined in these countries. Keeping in view the significance of the ACFE study, in the context of Pakistan, it seems that fraudulent activities put forth multiple complications for Pakistan's corporate sector. These complications include issues such as wastage of monetary resources, and the weak performance of the organizations (Omoolorun \& Abilogun, 2017). As a result, institutions in Pakistan face many adverse consequences, in terms of their competitiveness and reputation. Due to the aforementioned facts, the objective of our study is to explore the relationship between multiple attributes of the IAF and PD\&A of fraudulent activities, in the companies that are listed on the Pakistan Stock Exchange (PSX). Moreover, this study aims to identify the attributes that can significantly enhance the performance of IAF, and also to explain the significance of the attributes that make up the IAF in the PD\&A of the listed companies in Pakistan, that are taken into consideration. In terms of its empirical viability, this study will also prove to be helpful for internal audit professionals, in implementing effective internal audit systems, for the PD\&A of frauds, in 
the corporate sector of Pakistan. Additionally, the case study of Pakistan may also be used as a proxy for other developing countries, which may aid in the generalizing the findings of this research to a wider scale setting.

\section{Literature Review}

There is enough literature available in the archives when it comes to the role of the IAF and the PD\&A of fraudulent activities in various parts of the world. The Institute of Internal Auditors IA (2019) defines fraud as "an intentional activity which is designed to deceive someone for obtaining any illegal advantage". Sharma and Panigrahi (2013) stated in their study, that the capacity of the firms regarding the PD\&A of fraudulent activities, proves to be helpful, when the aim of organizations is to attain the goals/objectives of organizational accountability, and the most efficient use of their resources. In the recent past, more attention is being given to the I-Auditors, for the PD\&A of fraud, because in many organizations IA is now regarded as an important corporate tool which is used to address the threats of fraudulent practices (Salem, 2012). I-Auditors are the custodians for the IDF, which is primarily responsible for the PD\&A of fraudulent activities. Mui (2010) indicated that fraud consists of the intentional misrepresentation of facts and figure, in order to induce or incite someone to act in a deceitful manner. IA holds much value and significance for businesses, because it evaluates the adequacy of the IC system, and also makes efficient recommendations for the management to improve their control measures (Repousis et al., 2019).

When an External Auditor (E-Auditor) investigates the frauds that may have taken place in an organization, they focus more on the financial statement frauds. However, the I-Auditors focus on the wide variety of fraudulent practices, including misappropriation of assets as well (Badara \& Saidin, 2013). Fraud can also be defined as a duplicitous activity, involving criminal deception, in order to achieve an illegal advantage. According to Changwony (2015), in all the definitions of fraud, the one variable that is common, is the presence of deceit or dishonesty. In this context, IA is also known as the eye of the top management within the organization, which is used to counter any deceitful or dishonest practices that might go against the organizations code of ethics (Badara \& Saidin, 2013). Nardo (2011) stated that independence of the auditor is critically important for the IAF and the PD\&A of fraudulent activities to be effective. It is the management of the organization that influences the scope of the work that is crafted for the I-Auditors. An I-Auditor is considered to be an employee of the business, so it is difficult for this individual to be 
Fraud in Pakistan

independent from his employer. So, practically it is a challenging task for an I-Auditor to become an impartial stakeholder in the whole process (Turetken, Jethefer, \& Ozkan, 2019).

\subsection{IA Effectiveness and the PDEA of Fraud}

When it comes to the IA effectiveness, and the PD\&A of fraudulent activities, a conducive control environment, and the hiring of qualified and trusted individuals are important factors that need to be taken care of, in the context of the IAF (Mihret \& Yismaw, 2007). After the recruitment of individuals in the IAF, it is important that they must be trained continuously, so that they are able to take informed, effective and efficient decisions, and also make use of any special measures for PD\&A of fraudulent activities in a more systematic manner (Chang, Chen, Cheng \& Chi, 2019). Monisola (2013) identified a positive relationship between the PD\&A of fraudulent activities, and the effectiveness of the IAF. He also pointed out that there must be additional controls on errors, frauds, and irregularities in organizations with active IAF measures. Coram, Ferguson, and Moroney (2008) depicted that companies with proper IAF were able to detect more fraudulent activities, than those who did not choose to get the provision of IAF facilities. Hence, we can formulate our first hypothesis as;

H1: A + ive relationship exists between IA effectiveness and the PDEA of fraudulent activities.

\subsection{I-Auditor Independence and the PDEA of Fraudulent Activities}

Most of the extant literature that has been consulted for the purpose of this paper discusses the independence of an E-Auditor in the auditing process (Cohen \& Sayag, 2010). Later on, the critical role of an independent I-Auditor was considered to be a major factor for the effectiveness of the IA (Stewart \& Subramaniam, 2010). If the I-Auditor is a competent and efficient individual, then there are more chances of maintaining a superior quality of the PD\&A of fraudulent activities in any organization (Mugwe, 2012). According to Abu-Azza (2012) independence means the ability of the I-Auditor to give his calculated viewpoint, sans any external pressure, and also to give an opinion in an unbiased manner.

Following in the same stride, the audit committee must also contain independent directors. Moreover, the audit committee should play a critical role in the independence of the I-Auditor (Ali \& Handayani, 2019). In order to enhance the independence of the I-Auditor (Stewart \& Subramaniam, 2010), it would be beneficial to have a strong liaison 
between the I-Auditor and the audit committee (Goodwin-Stewart \& Kent, 2006b). If the IAF is independent, and impartial, then it is more effective to ensure the PD\&A of fraudulent activities. So, in this context, we can formulate our second hypothesis to be:

H2: A + ive relationship exists between the I-Auditor independence and the PD\&A of fraudulent activities.

\subsection{Training of the IAF Staff}

It does not come as a surprise that the IA department will be manifold efficient if its staff members are trained on a continuous basis. It is expected of an effective, and efficient, I-Auditor to possess relevant qualifications, knowledge, skills, ability, and the knowhow to carry out the required tasks, that will yield the most accurate results in the least amount of time and precious resources spent (McKee, 2006). One of the major reasons that I-Auditors potentially fails in their efforts to carry out the PD\&A of fraudulent activities, is the lack of training. Hence, the I-Auditor must be trained rigorously to gain sufficient knowledge and experience, in order to handle difficult situations that might emerge as a result of fraudulent activities (Hammersley, Johnstone, \& Kadous, 2011). Lloyd, Hunton and Thibodeau (2012) explained that I-Auditors, who have been trained for the PD\&A of fraudulent activities are more helpful than those who have not availed any training sessions. The primary reason for this is that during the training process of the I-Auditors, it is common for some individuals to be provided courses that are specifically about the PD\&A of fraudulent activities, while the others are provided general auditing courses. After examining the I-Auditor participation in training programs, researchers have pointed out that auditors who attend the programs that are specifically designed on the intricacies of the PD\&A of fraudulent activities, are more likely to detect fraud, instead of the others who have only been exposed to the general audit training programs. Thus, keeping in consideration these nuances, our third hypothesis can be:

H3: $\quad A+$ ive relationship exists between I-Auditor training and the PDEA of fraudulent activities.

\subsection{Qualification of the IA Staff}

Suitable and relevant qualifications of the IA staff is an essential characteristic that is mandatory for an effective IAF. Professionally qualified I-Auditors immensely improve the quality of the IA, in any dynamic business environment. Following the same stance, the head of the 
I-Audit should be highly and appropriately qualified, and must possess relevant certifications in the processes pertaining to auditing, fraud and risk management. Examples of these certifications can include the CIA 1 , $\mathrm{CFE}^{2}$ and $\mathrm{FRM}^{3}$, to name a few. If the auditor is qualified, then he should be able to make better decisions in a short span of time (Hutchinson \& Zain, 2009). Thus, assuming that this holds valid, out fourth hypothesis can be:

H4: A + ive relationship exists between the I-Auditor's qualification and the PDEA of fraudulent activities.

\subsection{Experience of the IA Staff}

It is no surprise that just like any other profession, relevant experience in the field of auditing increases the competency of the IAuditors. An I-Auditor, with a substantial amount of years invested into the audit experience, is in a better position to make the most accurate and calculated decisions for the organization. Moreover, such an individual is also prone to taking prompt actions due to a clear understanding of the PD\&A of fraudulent activities (Davidson, Goodwin-Stewart, \& Kent, 2005). Furthermore, experienced I-Auditors tend to make it a priority to deliver their tasks with attention to superior quality. Hutchinson and Zain (2009) explored the relationship between the professional experience of an IAuditor, and the firm's performance after an IA. Results revealed that experienced I-Auditors are vigilant enough to swiftly detect any noncompliance, and don't hesitate to take prompt actions for the PD\&A of fraudulent activities (Shaver, 2005; Zanzig \& Flesher, 2011). For the betterment of business operations, the implementation of internal controls, and the effective PD\&A of fraudulent activities, all team members of the IAF should possess work experience that is relevant to the activities of an Internal Audit. Keeping these assumptions in consideration, our fifth hypothesis is:

H5: $\quad A+$ ive relationship exists between I-Auditor experience and PDEA of fraudulent activities.

\footnotetext{
${ }^{1}$ Certified Internal Auditor

${ }^{2}$ Certified Fraud Examiner

${ }^{3}$ Financial Risk Manager
} 


\section{Conceptual Framework}

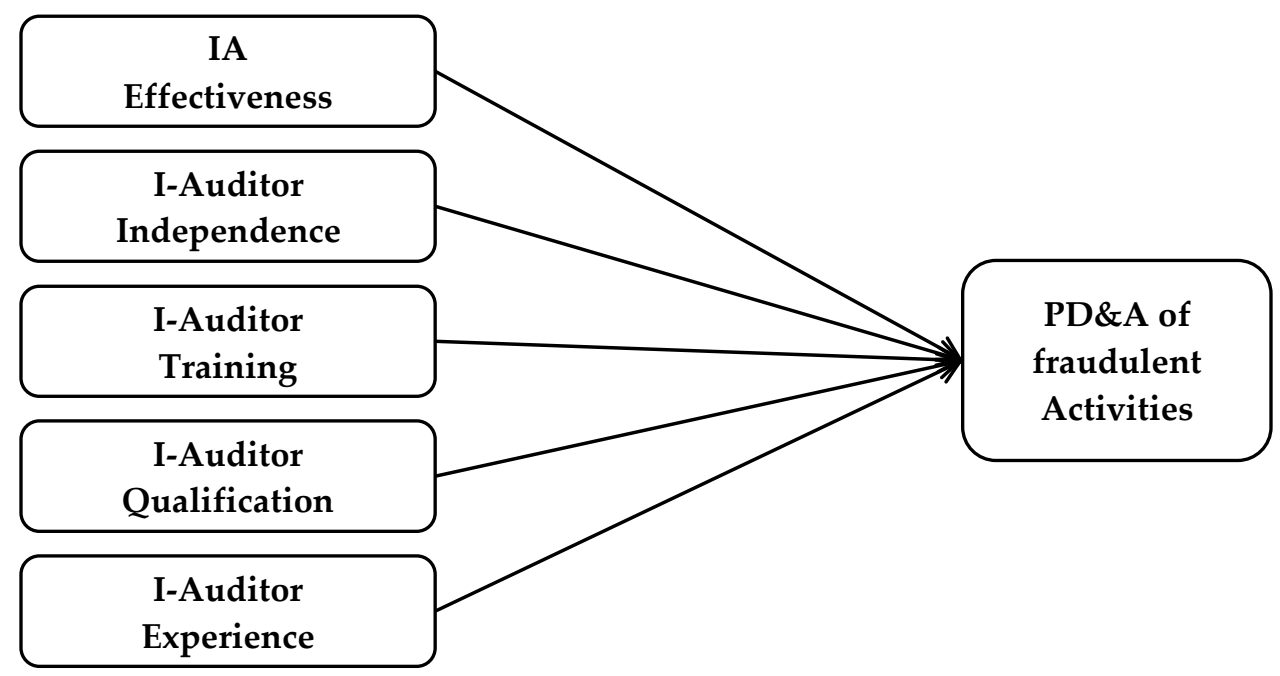

\section{Research Methodology}

This study aims to explore the relationship between the typical attributes of the IAF and the PD\&A of fraudulent activities. The sampling frame of this study consists of the staff members of the Internal Audit departments of the various listed companies of Pakistan. As the study is based on the employee's responses, there are less chances that a sampling bias would occur. The LIKERT scale based questionnaires have been used to collect the primary data, through the convenient sampling technique. Moreover, the overall target population of this research consists of the IAuditors, the staff of the IAF in companies, professionals who have an experience in the Accounting/Finance/IA industry, and faculty members who are teaching Accounting and Auditing. On addition to this, the sample size of this study was 291 respondents.

Section 1 of the questionnaire was based on questions pertaining to the demographic representation of individuals in this study. While section 2 is about the PD\&A of fraudulent activities (Dependent Variable) and the IA effectiveness, I-Auditor's independence, I-Auditor's training, IAuditor's qualification, and the I-Auditor's professional experience (Independent Variables). In order to analyze the data, the SPSS tool was deemed to be the most appropriate to read the results. The reliability and consistency of the instrument has been checked through the Cronbach Alpha (Field, 2009). Moreover, the regression analysis technique is used to determine the relationship between the above mentioned variables, and also to test the hypothesis. 
Fraud in Pakistan

To test the research hypothesis, the following model is formulated:

$\mathrm{FD}=f(\mathrm{IAE}, \mathrm{IAI}, \mathrm{IAT}, \mathrm{IAQ}, \mathrm{IAE})$

This model is empirically tested using the following equation:

$F D=\beta 0+\beta 1 I A E+\beta 2 I A \mathrm{I}+\beta 3 I A T+\beta 4 I A \mathrm{Q}+\beta 5 I A \mathrm{E}+\varepsilon$

\section{Where:}

$\begin{array}{ll}F D= & \text { PD\&A of fraudulent activities Variable } \\ \beta 0= & \text { Constant Term } \\ \beta 1 \text { to } \beta 5= & \text { The Coefficients } \\ I A E= & \text { I-Auditor Effectiveness } \\ I A \mathrm{I}= & \text { I-Auditor Independence } \\ I A T= & \text { I-Auditor Training } \\ I A Q= & \text { I-Auditor Qualification } \\ I A \mathrm{E}= & \text { I-Auditor Experience } \\ \varepsilon \quad= & \text { The Error Term }\end{array}$

\section{Research Findings: Analysis and Discussion}

The purpose of this study is to investigate the relationship between the attributes of the IAFs and the PD\&A of fraudulent activities. Therefore, this section explains the analysis and discussion of the research results obtained with the help of the questionnaire. The study begins with the demographic characteristics of the respondents. These include information on the respondents' gender, age, profession, sector and level of education. Then, it explains about the descriptive statistics, factor analysis results, reliability analysis and then finally, the regression analysis results are reported.

\subsection{Demographic Characteristics}

The questionnaires were distributed amongst Audit firms that were engaged in I-Audit, the staff of the IAF employed in companies, professionals who were experienced in Accounting/Finance/I-Audit, and faculty members teaching Accounting and Auditing in various institutions. About 300 questionnaires were distributed amongst the respondents, out of which 291 questionnaires were collected from 253 male respondents, and 38 female respondents. Out of this figure, $63.9 \%$ of the respondents belonged to the branch of audit, while the rest of the respondents fell under the category of accounting (10\%), management $(5.5 \%)$, and finance $(20.6 \%)$. 


\section{Table 1: Respondents general profile}

Position

\begin{tabular}{|c|c|c|c|c|c|}
\hline & & Frequency & Percent & Valid Percent & $\begin{array}{c}\text { Cumulative } \\
\text { Percent }\end{array}$ \\
\hline \multirow[t]{3}{*}{ Valid } & IA & 204 & 70.1 & 70.1 & 70.1 \\
\hline & $\mathrm{AP}$ & 87 & 29.9 & 29.9 & 100.0 \\
\hline & Total & 291 & 100.0 & 100.0 & \\
\hline \multicolumn{6}{|c|}{ Gender } \\
\hline & & Frequency & Percent & Valid Percent & $\begin{array}{c}\text { Cumulative } \\
\text { Percent }\end{array}$ \\
\hline \multirow[t]{3}{*}{ Valid } & Male & 253 & 86.9 & 86.9 & 86.9 \\
\hline & Female & 38 & 13.1 & 13.1 & 100.0 \\
\hline & Total & 291 & 100.0 & 100.0 & \\
\hline \multicolumn{6}{|l|}{ Age } \\
\hline & & Frequency & Percent & Valid Percent & $\begin{array}{c}\text { Cumulative } \\
\text { Percent }\end{array}$ \\
\hline \multirow[t]{4}{*}{ Valid } & $20-29$ & 25 & 8.6 & 8.6 & 8.6 \\
\hline & $30-39$ & 179 & 61.5 & 61.5 & 70.1 \\
\hline & $40-49$ & 87 & 29.9 & 29.9 & 100.0 \\
\hline & Total & 291 & 100.0 & 100.0 & \\
\hline \multicolumn{6}{|l|}{ Field } \\
\hline & & Frequency & Percent & Valid Percent & $\begin{array}{c}\text { Cumulative } \\
\text { Percent }\end{array}$ \\
\hline \multirow[t]{5}{*}{ Valid } & AGT & 29 & 10.0 & 10.0 & 10.0 \\
\hline & MNGT & 16 & 5.5 & 5.5 & 15.5 \\
\hline & AUDT & 186 & 63.9 & 63.9 & 79.4 \\
\hline & FIN & 60 & 20.6 & 20.6 & 100.0 \\
\hline & Total & 291 & 100.0 & 100.0 & \\
\hline
\end{tabular}

\subsection{Descriptive Statistics}

The first section of questionnaire revolves around the PD\&A of fraudulent activities. A total of ten questions were asked (Q1-Q10) regarding the detection of fraudulent activities, seven questions were asked (Q11-Q17) about the IA effectiveness, eight questions were asked (Q18-Q25) about independence of the I-Auditor, five questions were asked (Q26-Q30) about training of the I-Auditor, seven questions were asked (Q31-Q37) about the qualifications of the I-Auditor, and six questions were asked (Q38-Q43) about experience of the I-Auditor. The mean response of all the questions had a value less than 3.00, which indicates that all of the respondents concurred that the attributes of the IAFs are helpful in the detection of fraudulent activities. Moreover, the results of the standard deviations of Q5, Q16, Q17, Q24, Q25, Q26, Q30, Q34 and Q43 were greater than 1.00, which indicated that the perceptions of different respondents were different from each other in these particular questions. For other 
Fraud in Pakistan

questions the SD was computed to be less than 1.00, which shows that the respondents' perceptions were closer to each other. The descriptive statistics of all questions are shown in the following table:

Table 2: Descriptive statistics

\begin{tabular}{|c|c|c|c|}
\hline Question \# & Mean (SD) & Question \# & Mean (SD) \\
\hline 1 & $1.72(0.66)$ & 23 & $2.28(0.98)$ \\
\hline 2 & $1.92(0.81)$ & 24 & $2.71(\mathbf{1 . 0 6})$ \\
\hline 3 & $1.97(0.76)$ & 25 & $2.78(\mathbf{1 . 1 5})$ \\
\hline 4 & $2.13(0.95)$ & 26 & $2.22(1.06)$ \\
\hline 5 & $2.31(\mathbf{1 . 0 1})$ & 27 & $1.98(0.90)$ \\
\hline 6 & $2.02(0.79)$ & 28 & $2.08(0.92)$ \\
\hline 7 & $2.42(0.88)$ & 29 & $2.08(0.91)$ \\
\hline 8 & $2.29(0.90)$ & 30 & $2.28(\mathbf{1 . 0 1})$ \\
\hline 9 & $2.10(0.94)$ & 31 & $1.91(0.87)$ \\
\hline 10 & $2.15(0.98)$ & 32 & $2.24(0.89)$ \\
\hline 11 & $2.06(0.86)$ & 33 & $1.92(0.85)$ \\
\hline 12 & $2.43(0.83)$ & 34 & $2.42(1.09)$ \\
\hline 13 & $2.14(0.91)$ & 35 & $2.27(0.89)$ \\
\hline 14 & $2.43(0.98)$ & 36 & $2.26(0.94)$ \\
\hline 15 & $2.10(0.82)$ & 37 & $2.18(0.99)$ \\
\hline 16 & $2.43(\mathbf{1 . 0 1 )}$ & 38 & $1.90(0.86)$ \\
\hline 17 & $2.30(\mathbf{1 . 0 4 )}$ & 39 & $1.95(0.75)$ \\
\hline 18 & $2.46(0.99)$ & 40 & $2.20(0.89)$ \\
\hline 19 & $2.43(0.84)$ & 41 & $2.31(0.96)$ \\
\hline 20 & $2.31(0.93)$ & 42 & $1.99(0.90)$ \\
\hline 21 & $2.16(0.90)$ & 43 & $2.42(1.05)$ \\
\hline 22 & $1.96(0.81)$ & & \\
\hline
\end{tabular}

Source: Authors' Calculations

\subsection{Reliability Analysis}

The LIKERT scale type questionnaire was used to measure the reliability of the questionnaire. For this purpose, the Cronbach Alpha has calculated, which is essential for the overall reliability of the constructs. The calculated value of Cronbach alpha (0.893) shows that the responses which were generated from all the variables were reliable for data analysis.

Table 3: Reliability Analysis

\begin{tabular}{cc}
\hline \multicolumn{2}{c}{ Reliability Statistics } \\
\hline Cronbach's Alpha & N of Items \\
\hline .893 & 43 \\
\hline
\end{tabular}




\subsection{Correlations Matrix}

Furthermore, the Correlation Matrix was also examined to assess the reliability of the study. Ideally, the values should be between 0.30 and 0.8 . For this particular study, the values of most of the variables fell within the range, which showed that there is an adequate and sufficient correlation between the items of the responses. For all the variables defined, the values computed were less than 0.8 , hence, this was a confirmation that the factor analysis may be used for reliable results.

Table 4: Correlations Matrix

\begin{tabular}{lccccccc}
\hline & & DETA & EFFA & INDA & TRNA & QUAA & EXPA \\
\hline Pearson & DETA & 1.000 & .518 & .274 & .366 & .326 & .291 \\
Correlation & EFFA & .518 & 1.000 & .399 & .404 & .346 & .385 \\
& INDA & .274 & .399 & 1.000 & .436 & .314 & .402 \\
& TRNA & .366 & .404 & .436 & 1.000 & .525 & .476 \\
& QUAA & .326 & .346 & .314 & .525 & 1.000 & .452 \\
Sig. (1-tailed) & EXPA & .291 & .385 & .402 & .476 & .452 & 1.000 \\
& DETA &. & .000 & .000 & .000 & .000 & .000 \\
& EFFA & .000 &. & .000 & .000 & .000 & .000 \\
& INDA & .000 & .000 &. & .000 & .000 & .000 \\
& TRNA & .000 & .000 & .000 &. & .000 & .000 \\
& QUAA & .000 & .000 & .000 & .000 &. & .000 \\
& EXPA & .000 & .000 & .000 & .000 & .000 &. \\
& DETA & 291 & 291 & 291 & 291 & 291 & 291 \\
& EFFA & 291 & 291 & 291 & 291 & 291 & 291 \\
& INDA & 291 & 291 & 291 & 291 & 291 & 291 \\
& TRNA & 291 & 291 & 291 & 291 & 291 & 291 \\
& QUAA & 291 & 291 & 291 & 291 & 291 & 291 \\
& EXPA & 291 & 291 & 291 & 291 & 291 & 291 \\
\hline
\end{tabular}

Source: Authors' Calculations

\subsection{Factor Analysis Results and Factor Loading}

The most common method which is used to examine the construct validity, is the Factor Analysis (Hyuncheol, 2013). The major purpose of Factor Analysis is the reduction and filtration of the data. This helps to understand the key factors that need to be extracted, so as to gauge which ones leave a major impact on the study results. Factor Analysis has two common types; the first one is the Exploratory Factor Analysis, and the second one is the Confirmatory Factor Analysis. The Exploratory Factor Analysis is used when the questionnaire is not tested previously by any researchers of the study. And, the Confirmatory Factor Analysis is used in the studies where the questionnaire has been tested prior to distribution. 
Fraud in Pakistan

We used the Exploratory Factor Analysis because the questionnaire was not previously tested by any other researcher. The use of the exploratory Factor Analysis is beneficial in order to understand the structure of the variables, besides also measuring the accuracy of the results.

The appropriateness of the collected data must be tested further, in order to conduct the Factor Analysis, and the sample size taken into consideration must also be sufficient for the accuracy of the results. The adequacy of sampling is determined by conducting the Kaiser-MeyerOlkin (KMO). The sample size of this research $(n=291)$, and the KMO result of 0.783 , indicates good sampling adequacy. The Principal Component Analysis (PCA) method has been used for the extraction of the factors to in order to show "how a particular variable contributes to that component".

Table 5: KMO and Bartlett's Test

\begin{tabular}{ccc}
\hline \multicolumn{2}{c}{ Kaiser-Meyer-Olkin Measure of Sampling Adequacy. } & .783 \\
\cline { 1 - 2 } Bartlett's Test of Sphericity & Approx. Chi-Square & 3113.880 \\
\cline { 2 - 3 } & Df & 903 \\
& Sig. & .000 \\
\hline
\end{tabular}

After the extraction of the relevant factors, factor loading was applied to show which variables load on to these defined factors. After examining the extraction of the factors with the extraction method PCA, there are some variables that had a higher factor loading on a specific factor, while smaller loading on the other factors. The factor loading values that were more than 0.4 were considered to have a higher participation rate (Hair et al., 1995). Moreover, the Varimax rotation methodology has also been used for a better interpretation of the results in the factor analysis. After the factor loading process, it has been observed that the questions with a value that went above 0.4 had a high participation, but questions such as Q3, Q8, Q12, Q13, Q15, Q18, Q22, Q25, Q32, Q34, Q35, Q37, Q40, Q42 and Q43, had a lesser participation in the factors, because their value was less than 0.4.

The Factor Analysis results and Factor Loadings are depicted in Appendix1 and 2

\subsection{Regression Results and Hypothesis Testing}

The primary purpose of the regression results is to explore the relationship between different variables, as identified in the research model. The model summary (Table 6) identifies the relationship between the attributes of the IAF and the PD\&A of fraudulent activities. The model 
is considered to be stealthy if the value of the R square is larger. It is noteworthy that this study is dependent on the perception of the respondents. This perception is collected through the questionnaire that was circulated in the target sample. Results reveal that the $\mathrm{R}$ square value is more than $25 \%$, which means that it is considered as a good to fit value (Thompson, 2002). The assumptions of autocorrelation are tested with the help of the Durbin-Watson test, the value for which is closer to 2, and is acceptable (Field, 2009). The result of the DW test of this study has come out to be 1.677, which is closer to 2 , and reflects the absence of autocorrelation among the residuals.

\section{Table 6: Regression results}

Model Summary ${ }^{b}$

\begin{tabular}{|c|c|c|c|c|c|c|c|c|c|c|}
\hline \multirow[t]{2}{*}{ Model } & \multirow[t]{2}{*}{$\mathbf{R}$} & \multirow{2}{*}{$\begin{array}{c}\mathbf{R} \\
\text { Square }\end{array}$} & \multirow{2}{*}{$\begin{array}{c}\text { Adjust } \\
\text { ed R } \\
\text { Square }\end{array}$} & \multirow{2}{*}{$\begin{array}{l}\text { Std. } \\
\text { Error of } \\
\text { the } \\
\text { Estimate }\end{array}$} & \multicolumn{5}{|c|}{ Change Statistics } & \multirow{2}{*}{$\begin{array}{c}\text { Durbin } \\
\text { - } \\
\text { Watson }\end{array}$} \\
\hline & & & & & $\begin{array}{c}\mathbf{R} \\
\text { Square } \\
\text { Change }\end{array}$ & $\begin{array}{c}\mathrm{F} \\
\text { Change }\end{array}$ & df1 & df2 & $\begin{array}{c}\text { Sig. F } \\
\text { Change }\end{array}$ & \\
\hline 1 & $.553^{a}$ & .306 & .294 & .36934 & .306 & 25.144 & 5 & 285 & .000 & 1.677 \\
\hline
\end{tabular}

a. Predictors: (Constant), EXPA, EFFA, INDA, QUAA, TRNA

b. Dependent Variable: DETA

The ANOVA table (Table 7) shows the model significance by considering the F-statistics value, ( $\mathrm{F}=25.144)$ which shows that there exists a sturdy relationship between the predictors, and the outcome of the regression variables. So, this validates that it is the best model to predict the PD\&A of fraudulent activities.

Table 7: ANOVAa

\begin{tabular}{ccccccc}
\hline & Model & $\begin{array}{c}\text { Sum of } \\
\text { Squares }\end{array}$ & Df & Mean Square & F & Sig. \\
\hline 1 & Regression & 17.150 & 5 & 3.430 & 25.144 & $.000^{\mathrm{b}}$ \\
& Residual & 38.877 & 285 & .136 & & \\
& Total & 56.027 & 290 & & & \\
\hline
\end{tabular}

a. Dependent Variable: DETA

b. Predictors: (Constant), EXPA, EFFA, INDA, QUAA, TRNA

Furthermore, the tolerance ( $\mathrm{t}$ value) of all the variables is greater than a value of 0.10 , and the VIF value is less than 10 . The correlation table shows that all the paired values are less than 0.8 . Hence, this indicates that there is no multicollinearity between the factors that are considered. 


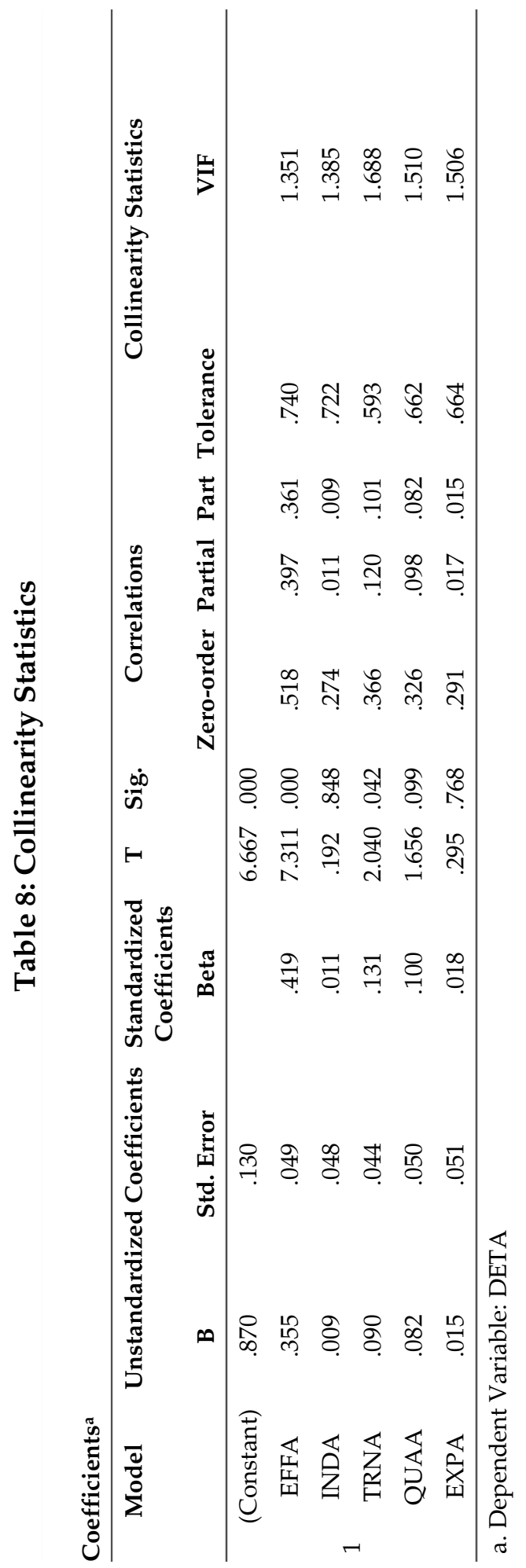


The Coefficient table (Table 8) shows that the three independent variables (IA Effectiveness, I-Auditor Training, and I-Auditor Qualification) were positively and significantly contributing to the dependent variable (the PD\&A of fraudulent activities). But two of the independent variables (I-Auditor Independence, and I-Auditor Experience) were positively, but not significantly contributing to the dependent variable. The Beta sign came out to be positive, so the entire proposed hypothesis became acceptable. This is because all the five hypotheses stated that there is a positive relationship with the dependent variable. In a nutshell, based on the statistical significance, only three of the independent variables contributed significantly, and the remaining two independent variables could not make a significant contribution to the dependent variable.

Keeping in view the results and the foregoing discussion, it is evident that the PD\&A of fraudulent activities attracts more attention during the period of an economic crises. In business organizations, the IAF is considered as a major tool that is utilized to prevent, as well as detect frauds. This department evaluates the effective operations of the accounting function in an organization. Most commonly, the individuals who resort to committing fraud are members of the administration, or the employees. So, the active role of the I-Auditor is expected for fraud curtailment in these companies. The department of IA must be efficient in maintaining the quality and reliability of the financial reporting systems of the businesses. In order to preclude such problems, companies must take into account certain key measures to make sure that fraudulent activities do not become successful in their organizations. For instance, companies should establish a strong IC and audit system, they should only hire those IA individuals who have ample experience in the field, and are trusted by the organization, and also create a positive IC environment. Training of IA is a mandatory practice that is used to develop the skill set required to prevent, and detect the fraud. Due to these factors, the recovery costs can be high for the companies that have been victim of frauds. In order to secure the financial data, there must be an effective and efficient system of IA, in order to identify the financial irregularities in the system. The results of this study contribute in the form of imperative insights that delve into which variables play a significant roles in the PD\&A of fraudulent activities.

\section{Concluding Remarks}

This research is conducted in order to investigate the relationship between the attributes of the IAF and the PD\&A of fraudulent activities. 
The questionnaires were collected from respondents belonged to the companies listed on Pakistan Stock Exchange. Moreover, the data was collected using the Convenient Sampling Technique, and the Likert scale was used to prepare the questionnaire. The results of the descriptive statistics revealed the details regarding the demographic questions, the IAF and the PD\&A of fraudulent activities. Furthermore, the results of the regression analysis revealed that all of the five independent variables positively affected the PD\&A of fraudulent activities. However, three of the independent variables (IAE, IAT, and IAQ) were statistically significant, whereas two of the variables (IAI, and IAE) were statistically insignificant. In the light of these results, it is recommended that the IAF should be more independent, and effective in order to attain the required results. Additionally, Firms should also focus on the required qualifications and proper professional training of the staff of IAF.

In empirical terms, this study is important for policy makers, regulators and businesses in general. The owners, founders and HR managers can benefit from this study during the hiring process of the IA staff, especially in terms of putting critical importance on their professional certifications and experience. Companies should also invest in the training of their audit staff, not only to establish effective IA systems and procedures, but also to create an effective control environment. This study has many recommendations for the business and organizational world. For instance, it proposes that more independence should be given to the I-Auditors, which is only possible with the support of the senior management. The management of organizations should also introduce modern technologies and software packages for effective working of the IA department. Certified and experienced staff should be put through a rigorous hiring process.

Keeping in mind the results of this study, we can now shed some light on the limitations that are put forth. Firstly, this study is limited to the employee's responses, which may not always be objective and unbiased. Moreover, the effectiveness of the IA on a firm's overall performance is not examined, for which future studies are recommended to be undertaken. Additionally, extensive studies for other developing countries may also be conducted, in order to determine the relationship between the PD\&A of fraudulent activities and the IAF. 


\section{References}

Abu-Azza, W. (2012). Perceived effectiveness of the Internal Audit function in Libya: A qualitative study using Institutional and Marxist theories. (Doctoral dissertation, The University of Southern Queensland, Australia). Retrieved from https://eprints.usq.edu.au/22330/.

Ali, M. O., \& Handayani, W. (2019). Impact of Audit Committee Expertise and Audit Committee Independence on Internal Audit Function. International Journal of Social Science and Economic Research, 3(3), 950-958.

Al Matarneh, G. F. (2011). Factors determining the IA quality in banks: Empirical evidence from Jordan. International Research Journal of Finance and Economics, 73(1), 99-108.

Alvarez, I. G. (2012). Impact of CO2 emission variation on firm performance. Business Strategy and the Environment, 21(7), 435-454.

Azim, M. I., \& Azam, S. (2016). Bernard Madoff's 'Ponzi Scheme': Fraudulent behavior and the role of auditors. Accountancy Business and the Public Interest, 15(1), 122-137.

Badara, M. a. S., \& Saidin, S. Z. (2013). Impact of the effective internal control system on the IA effectiveness at local government level. Journal of Social and Development Sciences, 4(1), 16-23.

Balaciu, D. E., Bogdana, V., Feleaga, L., \& Popa, A.-L. (2014). " Colorful" approach regarding creative accounting. An introspective study based. Accounting and Management Information Systems, 13(4), 643.

Bekiaris, M., Efthymiou, T., \& Koutoupis, A. G. (2013). Economic crisis impact on corporate governance and IA: the case of Greece. Corporate Ownership and Control, 11(1), 55-64.

Boone, H. N., \& Boone, D. A. (2012). Analyzing likert data. Journal of extension, 50(2), 1-5.

Chang, Y. T., Chen, H., Cheng, R. K., \& Chi, W. (2019). The impact of internal audit attributes on the effectiveness of internal control over operations and compliance. Journal of Contemporary Accounting $\mathcal{E}$ Economics, 15(1), 1-19. 
Fraud in Pakistan

Cohen, A., \& Sayag, G. (2010). The effectiveness of internal auditing: an empirical examination of its determinants in Israeli organisations. Australian Accounting Review, 20(3), 296-307.

Coram, P., Ferguson, C., \& Moroney, R. (2008). IA, alternative IA structures and the level of misappropriation of assets fraud. Accounting $\mathcal{E}$ Finance, 48(4), 543-559.

Changwony, M. K., \& Rotich, G. (2015). Role of IAF in promoting effective corporate governance of commercial banks in Kenya. International Journal of Business and Law Research, 3(1), 15-33.

Davidson, R., Goodwin-Stewart, J., \& Kent, P. (2005). Internal governance structures and earnings management. Accounting $\mathcal{E}$ Finance, 45(2), 241-267.

Drogalas, G., Pazarskis, M., Anagnostopoulou, E., \& Papachristou, A. (2017). The effect of IA effectiveness, auditor responsibility and training in fraud detection. Accounting and Management Information Systems, 16(4), 434-454.

Daniela, P., \& Attila, T. (2013). Internal audit versus internal control and coaching. Procedia Economics and Finance, 6(1), 694-702.

El-Sayed Ebaid, I. (2011). IAF: an exploratory study from Egyptian listed firms. International Journal of law and management, 53(2), 108-128.

Field, A. (2009). Discovering statistics using SPSS. New York: Sage.

Gates, S., Prachyl, C. L., \& Sullivan, C. (2016). Using report to the nations on occupational fraud and abuse to stimulate discussion of fraud in accounting and business classes. Journal of Business and Behavioral Sciences, 28(1), 106-115.

George, D., Theofanis, K., \& Konstantinos, A. (2015). Factors associated with IA effectiveness: Evidence from Greece. Journal of Accounting and Taxation, 7(7), 113-122.

Goodwin-Stewart, J., \& Kent, P. (2006a). The use of IA by Australian companies. Managerial Auditing Journal, 21(1), 81-101. 
Goodwin-Stewart, J., \& Kent, P. (2006b). Relation between external audit fees, audit committee characteristics and IA. Accounting $\mathcal{E}$ Finance, $46(3), 387-404$.

Hair, J.F. u.a. (1998). Multivariate Data Analysis: with Readings, 5. Ed., New Jersey: Prentice Hall.

Hammersley, J. S., Johnstone, K. M., \& Kadous, K. (2011). How do audit seniors respond to heightened fraud risk? Auditing: A Journal of Practice E Theory, 30(3), 81-101.

Hutchinson, M. R., \& Zain, M. M. (2009). IA quality, audit committee independence, growth opportunities and firm performance. Corporate Ownership and Control, 7(2), 50-63.

Hyuncheol, K. (2013). A Guide on the Use of Factor Analysis in the Assessment of Construct Validity. Journal of Korean Academy of Nursing, 43(5), 587-594.

Lee, G., \& Fargher, N. (2013). Companies' use of whistle-blowing to detect fraud: An examination of corporate whistle-blowing policies. Journal of business ethics, 114(2), 283-295.

Leung, P., Cooper, B. J., \& Perera, L. (2011). Accountability structures and management relationships of IA: An Australian study. Managerial Auditing Journal, 26(9), 794-816.

Lloyd Bierstaker, J., Hunton, J. E., \& Thibodeau, J. C. (2012). Does Fraud Training Help Auditors Identify Fraud Risk Factors?. In Bobek Schmitt, D. (Ed.), Advances in Accounting Behavioral Research (pp. 85100). London: Emerald Group Publishing Limited.

McKee, T. E. (2006). Increase your fraud auditing effectiveness by being unpredictable! Managerial Auditing Journal, 21(2), 224-231.

Mihret, D. G., \& Yismaw, A. W. (2007). Internal audit effectiveness: an Ethiopian public sector case study. Managerial Auditing Journal, 22(5), 470-484.

Monisola, O. (2013). Effect of IA on prevention of frauds, errors and irregularities in corporate organisation. Research Journal of Finance and Accounting, 4(19), 103-108. 
Fraud in Pakistan

Mugwe, M. N. (2012). The Relationship between the Independence and objectivity of the IAF and Earnings per Share (EPS) in companies listed in NSE (Doctoral dissertation, The University of Nairobi, Nairobi, Kenya). Retrieved from http://erepository.uonbi.ac.ke /handle/11295/10762

Mui, G. Y. (2010). Auditor expert performance in fraud detection: The case of IAuditors. (Doctoral dissertation, The University of Queensland, Australia). Retrieved from https://espace.library.uq.edu.au/view /UQ:211780

Nardo, M. (2011). Economic crime and illegal markets integration: a platform for analysis. Journal of Financial Crime, 18(1), 47-62.

Omoolorun, A. J., \& Abilogun, T. O. (2017). Fraud free financial report: A conceptual review. International Journal of Academic Research in Accounting, Finance and Management Sciences, 7(4), 83-94.

Prawitt, D. F., Sharp, N. Y., \& Wood, D. A. (2012). Internal audit outsourcing and the risk of misleading or fraudulent financial reporting: Did Sarbanes-Oxley get it wrong?. Contemporary Accounting Research, 29(4), 1109-1136.

Repousis, S., Lois, P., \& Veli, V. (2019). An investigation of the fraud risk and fraud scheme methods in Greek commercial banks. Journal of Money Laundering Control, 18(3), 145-156.

Salem, M. S. (2012). An overview of research on auditor's responsibility to detect fraud on financial statements. Journal of Global Business Management, 8(2), 218.

Sharma, A., \& Panigrahi, P. K. (2013). A review of financial accounting fraud detection based on data mining techniques. Retrieved from https://arxiv.org/abs/1309.3944

Shaver, D. (2005). Characteristics of corporate boards in single-industry and conglomerate media companies. International Journal on Media Management, 7(3-4), 112-120.

Soltani, B. (2014). The anatomy of corporate fraud: A comparative analysis of high profile American and European corporate scandals. Journal of business ethics, 120(2), 251-274. 
Stewart, J., \& Subramaniam, N. (2010). IA independence and objectivity: emerging research opportunities. Managerial Auditing Journal, 25(4), 328-360.

Thompson, B. (2002). What future quantitative social science research could look like: Confidence intervals for effect sizes. Educational Researcher, 31(3), 25-32.

Turetken, O., Jethefer, S., \& Ozkan, B. (2019). Internal audit effectiveness: operationalization and influencing factors. Managerial Auditing Journal, 35(2), 238-271.

Zanzig, J. S., \& Flesher, D. L. (2011). Internal Auditors speak out on controlling employee fraud. In Jeffrey, C. (Ed.) Research on Professional Responsibility and Ethics in Accounting (pp. 225-250), London: Emerald Group Publishing Limited. 
Factor Analysis Results

Component Matrixa

\begin{tabular}{|c|c|c|c|c|c|c|}
\hline \multirow[t]{2}{*}{ Questions } & \multicolumn{6}{|c|}{ Component } \\
\hline & 1 & 2 & 3 & 4 & 5 & 6 \\
\hline @1 & .362 & .015 & .443 & -.097 & .105 & -.119 \\
\hline @2 & .324 & .029 & .432 & -.104 & .203 & .022 \\
\hline @3 & .292 & .150 & .338 & -.275 & .291 & .075 \\
\hline$@ 4$ & .291 & .403 & .351 & .089 & .260 & .096 \\
\hline$@ 5$ & .224 & .473 & .399 & .027 & .259 & -.088 \\
\hline @6 & .303 & -.121 & .477 & .207 & .153 & -.195 \\
\hline @7 & .348 & .461 & .095 & -.208 & .044 & -.248 \\
\hline$@ 8$ & .392 & -.098 & .086 & -.167 & -.160 & .278 \\
\hline$@ 9$ & .311 & -.093 & .206 & .089 & -.240 & .446 \\
\hline @10 & .493 & -.052 & .176 & .017 & -.316 & .089 \\
\hline$@ 11$ & .482 & -.117 & .230 & -.036 & -.164 & .229 \\
\hline$@ 12$ & .396 & -.208 & .138 & -.200 & -.172 & .229 \\
\hline$@ 13$ & .344 & .045 & .302 & .093 & -.114 & .276 \\
\hline$@ 14$ & .454 & .376 & -.033 & -.034 & -.261 & .124 \\
\hline @15 & .349 & -.054 & .176 & -.153 & -.008 & .180 \\
\hline$@ 16$ & .374 & .475 & .021 & -.020 & -.275 & .065 \\
\hline$@ 17$ & .409 & .464 & .014 & .038 & -.191 & -.112 \\
\hline$@ 18$ & .214 & .026 & -.065 & .231 & -.059 & -.195 \\
\hline$@ 19$ & .216 & -.086 & .070 & .567 & -.052 & -.059 \\
\hline$@ 20$ & .327 & .406 & .000 & .448 & -.120 & -.224 \\
\hline$@ 21$ & .409 & -.128 & .142 & .236 & -.051 & -.017 \\
\hline$@ 22$ & .343 & -.125 & -.203 & .054 & -.005 & -.207 \\
\hline$@ 23$ & .536 & -.051 & -.386 & -.055 & -.064 & .090 \\
\hline$@ 24$ & .289 & .457 & -.333 & .306 & .166 & .165 \\
\hline$@ 25$ & .348 & .257 & -.423 & .046 & .228 & .176 \\
\hline$@ 26$ & .605 & -.089 & -.237 & -.157 & -.001 & -.006 \\
\hline$@ 27$ & .518 & -.136 & -.184 & .158 & -.020 & -.172 \\
\hline$@ 28$ & .538 & -.119 & -.156 & .202 & -.053 & .015 \\
\hline$@ 29$ & .515 & -.216 & .088 & .031 & -.068 & -.028 \\
\hline$@ 30$ & .416 & .314 & -.254 & -.217 & .073 & -.125 \\
\hline @31 & .522 & -.338 & -.065 & -.116 & .209 & -.066 \\
\hline$@ 32$ & .366 & -.313 & -.182 & -.211 & .094 & -.022 \\
\hline @33 & .444 & -.199 & -.054 & .155 & .142 & -.347 \\
\hline$@ 34$ & .366 & .326 & -.379 & -.150 & -.046 & -.084 \\
\hline
\end{tabular}




\begin{tabular}{ccccccc}
\hline Questions & \multicolumn{7}{c}{ Component } \\
\cline { 2 - 7 } & $\mathbf{1}$ & $\mathbf{2}$ & $\mathbf{3}$ & $\mathbf{4}$ & $\mathbf{5}$ & $\mathbf{6}$ \\
\hline$@ 35$ & .389 & -.246 & .202 & -.088 & -.344 & -.385 \\
$@ 36$ &. $\mathbf{4 3 1}$ & -.292 & .108 & -.107 & -.168 & -.380 \\
$@ 37$ & .365 & -.102 & -.061 & -.297 & .126 & -.257 \\
$@ 38$ & .469 & .154 & .025 & -.183 & .231 & .076 \\
$@ 39$ & .355 & -.141 & -.002 & .219 & .535 & .123 \\
$@ 40$ & .342 & -.300 & -.069 & .188 & .268 & .198 \\
$@ 41$ & .438 & -.393 & -.275 & -.109 & .158 & .136 \\
$@ 42$ & .374 & -.246 & -.119 & .321 & -.067 & .176 \\
$@ 43$ & .365 & .288 & -.279 & -.173 & -.081 & .072 \\
\hline
\end{tabular}

Extraction Method: Principal Component Analysis. 


\section{Factor loadings}

\section{Factors/ Items Description}

Factor Loadings

Detection of fraudulent activities

1. The I-Auditor detects unauthorized transactions

2. The I-Auditor detects falsifying of financial statements

3. The I-Auditor detects false valuation of company assets

4 The I-Auditor detects fraud by employees

5 The I-Auditor detects bribery and/or kickbacks

6 The I-Auditor detects payroll inaccuracy

7 The I-Auditor detects skimming of incoming funds

8 The I-Auditor applies techniques to detect fraud

9 System of IC prevents mistakes

10 System of IC detects fraud effectively

IA Effectiveness

11 The IA system improves the operation of the business

12 The staff of IA is deemed sufficient

13 IA ensures the economical, effective and efficient use of resources

14 The audit procedures and evidence collections are completed on time .454

15 There are disciplinary consequences to perpetrators of fraud

16 There are special control services in all departments of the business $\quad .475$

17 The safeguards of the control system prevent illegal activities $\quad .464$

I-Auditor Independence

18 There is independence of the I-Auditor

19 There is cooperation of the I-Auditor with the members of administration .567

20 I-Auditor report directly to administration about finding errors $\quad .448$

21 IA is carried out only by staff of IA 409

22 The top administration hires E-Auditor for check

23 I-Auditor staff receive full cooperation, access to records and information

24 The I-Auditor perform auditing activities without any interference from anybody

25 I-Auditor feel free to include any audit finding in audit report

\section{I-Auditor Training}

26 The staff of IA is trained continuously

27 Training provided of I-Auditor are helpful to improve skills 


\section{Factors/ Items Description}

\section{Factor Loadings}

28 Training to IAF are helpful for PD\&A of fraudulent activities

29 The management introduce IA with new technology, policy and procedures

30 Training are helpful to carrying out IC function

\section{I-Auditor Qualification}

31 I-Auditor are certified

32 Most of I-Auditors have certification in auditing

34 The I-Auditor who has high qualification can deal with any issue inside the department of IA

35 The qualification of I-Auditor help to identify any noncompliance activities

36 The qualification of I-Auditor help to performed with modern technology

37 Qualified I-Auditors perform IA services in accordance with the International Standards for the Professional Practice of IA

I-Auditor Experience

38 The staff of IA is experienced

39 I-Auditor provide useful recommendation on control systems

40 The I-Auditors are capable to determine the nature and frequency of noncompliance activities

41 I-Auditors have the experience and expertise to address corporate risk management problems within the organization

42 The recommendation, criticism and information provided by IA used for decision making

43 The IA report are highly considered for decision making 